\title{
Editor's Comments
}

The Journal of Teaching and Learning focuses on issues of teaching and learning - obviously. However, teaching and learning are anything but straightforward, in all their many permutations and implications in school and in life. In this issue, each article approaches teaching and/or learning from a different vantage point: from the view of teachers, of teacher candidates, of school students, of administrators, ministries of education, and curriculum designers, in Canada, Africa, and Asia. Despite the apparent diversity of this collection, the articles contain many areas of overlap and points of convergence.

I know how often I read one article within a journal, usually because I am doing my online research and have found an article that seems applicable. This impoverishes the reader - it is what I have come to think of as 'fast reading', akin to fast food. We swoop up to the take-out window, grab our burger and drink, and drive on. In the good ol' days, a trip to the library was the only way to do a literature search, and that involved card catalogues (yes, some of you know what I am talking about), and hours in the stacks. Both in the card catalogues, if you were doing a subject search, and in the stacks, the eye was inevitably drawn to the entries or books that were filed to each side, or sitting nearby. And, when time permitted, that usually meant pulling multiple books from the shelves and delighting in chance discoveries. As online searches have largely replaced haunting the stacks, and 'advanced' searches have allowed us to narrow our target, we can often go directly to an individual article or book chapter, save the file, and look no further.

While taking the Journal of Teaching and Learning online, and providing open access has been a great boon to our ever-increasing readership, I wonder, "What are we missing?" What has been lost, from the days when we sat down with a hard copy in our hands, started by scanning the table of contents, and then dove in, reading articles willy-nilly, in or out of order? I encourage you to read more than one of the articles in this issue, and to read 'across' for meanings that can be found between texts. Teacher candidates in Tanzania and in Ontario or students in Taiwan prepping for exit language proficiency exams, share similar challenges in learning, applying, and adapting to new problems. And those who are designing curriculum and trying to motivate learners, ask similar questions - about what knowledge matters and how to tap into students' interest and motivation - whether they are teaching French to grade 9 students in Canada or English as a Second Language to university students in Taiwan. The issues facing rural schools in Kenya may seem very distant from problems of bullying in Canadian schools; but for the teachers who face these issues, support from government and local school boards can make all the difference to programs that effect social change.

Here are a few of the ideas that caught my attention, in no particular order.

Anyone who has taught or studied in a Teacher Education program knows the constant emphasis on 'reflective practice'. It at times seems like a meaningless mantra, so pervasive is the term. Buzza, Kotsopoulos, Mueller, and Johnston bring rigour to applying the concept of self-reflective practice, with a study of 91 pre-service candidates during the course of one year. The authors both define reflective practice, and develop a rubric to measure levels of reflection. The habitual use of 'reflections' as assessment strategies in teacher education programs can become meaningless time-filler: "Responses seemed to 
be technical or even disengaged, as if the analysis were being done for its own sake, rather than as a means to further learning or understanding" (Buzza et al.) In this research, teacher candidates were asked to provide written responses to 20 reflective questions as they went out on practicum placements. Those responses were coded and the results provide a surprisingly rigorous look at how Teacher Candidates engage with reflective practice, at different levels and complexity. Recommended reading for everyone teaching in a Faculty of Education!

In Ontario, French and art are both subject areas that see a quick drop off rate after students complete the minimum single credit for graduation. Rover undertook a case study in which she provided an integrated project, combining art and core French, within an applied program stream. Many factors affect enrolment and continued enrolment in French courses, including charismatic teachers; but Rover's research, which asked students for their viewpoint, provides a smart approach.

Kajoro, Chirure, and Simiyu provides a fascinating portrait of teacher education in three East African countries, Kenya, Nigeria, and Tanzania. The central thesis of their paper is that excellence in learning depends on excellence in teaching, which in turn depends on excellence in teacher education. The implication of this review reaches well beyond the pedagogical or even administrative, into the political and cultural context of teaching:

Governments need to take drastic steps to review the teachers' working conditions including remunerations so that teachers can focus their attention solely on the teaching and learning process rather than divide their time and attention between teaching, offering private tuition, and engaging in small scale businesses to make ends meet. (Kajoro et al.)

Ontario has just suffered through another round labour unrest in the education sector, triggered by the provincial government legislating a contract settlement and teachers withdrawing voluntary activity. The real and perceived responsibilities of teachers continually increase due to expectation creep. Parents and students come to feel entitled to a whole range of extra curricular activities, while the government pressures schools to raise academic outcomes. While teachers in Canada may not have to "engage in small scale businesses to make ends meet", they certainly struggle to "focus their attention" on teaching and learning while providing tens of thousands of unremunerated volunteer hours to the community.

Robertson, Thomson, and Barber take us through the process and results of implementing a new program in K-8 classrooms on Body Image. They surveyed and interviewed teachers a year after implementation of the program at several schools. Their findings contain many points of overlap and common concern with another article in this issue by Ihnat and Smith on Bullying. Ihnat and Smith conducted their study with pre-service teachers, to determine whether a workshop on bullying intervention would change responses to hypothetical bullying scenarios. In both studies, the attitudes of participants pre-intervention are an important factor, as teacher and teacher candidates are not immune to socially constructed ideas around difference including attitudes towards obesity. Furthermore, their own body image or bias may skew their response to victims of bullying. Both studies should be included as required reading for those 
planning teacher education programs as well as for Ministry mandated curriculum and professional development. We are still a long way from providing students with a safe schools and providing teachers with the strategies and supports needed to keep them that way.

Finally, Pan and Newfields write about the "washback" effect from English proficiency tests, an exit requirement at a number of universities on the Pacific rim. I could not read this without comparing it to the drive to standardized testing in Ontario schools. Pan and Newfields found that there was no "perceived" value in the testing activity, and "hence, no increased motivation." While some teachers felt increased pressure to provide test preparation, there was marginal if any increase in motivation for students to study more, or, critically, to "expand their learning autonomy." The low pass rates seemed to actually suppress what motivation students might have had. This study invites reflection, on how tests influence teaching and learning; and also on the growth industry of English as an Additional Language and how institutions of higher learning are bending to a perceived global demand for fluency in the lingua franca of commerce if not of academia.

Read one, read two, or even better, read them all.

A final note: the Editor's Chair is a wonderful spot to occupy, but the demands of it are heavy, while the benefits are high. So I am happy to turn over the keys to our (virtual) office to Chris Greig and Andrew Allen. They are not only sharing the job but have already begun to involve graduate students in learning the ropes. I want to thank Kimberly Crosby Hillier, who has helped me with proof reading and readying this issue for publication. We all owe a debt of gratitude to graduate students who choose to work along side us. Thank you Kim!

Terry Sefton 